\title{
DISPERSIÓN URBANA Y CONFORMACIÓN DE PERIFERIAS: EL CASO DE MADRID
}

\section{Urban Sprawl and configuration of urban peripheries: the case of Madrid}

\section{De Láncer Salas, Victoria Amelia}

Candidata a Doctorado.

Escuela de Arquitectura, Universidad de Alcalá, victoria.delancersalas@gmail.com

Director de tesis: Dr. Arq. José Juan Barba

\section{RESUMEN}

La ciudad de Madrid es generalmente asociada al modelo urbano compacto y denso. Sin embargo, es posible afirmar que su periferia carece de los elementos necesarios que la categoricen dentro de este modelo, llegando incluso a definirse por varios de los parámetros que describen al modelo urbano disperso y de baja densidad, también conocido como Urban Sprawl.

Si bien el modelo de Sprawl es asociado a la suburbia norteamericana donde priman las viviendas unifamiliares, al hacer una revisión bibliográfica del este concepto, se aprecia que este va mucho más allá de esta tipología residencial, e incluye parámetros de composición, uso de suelo, estructura y morfología urbana, que en muchos casos coincide con lo encontrado en el análisis de los PAU.

De esta manera, Madrid se presenta como el laboratorio idóneo donde estudiar la complejidad de los procesos urbanos condicionados por distintas corrientes políticas urbanas, ya que dentro de un mismo término municipal se contraponen el modelo compacto tradicional, el modelo de crecimiento tipo ensanche y el modelo disperso.

A partir del análisis realizado, se presenta una imagen de la ciudad actual y los factores que han configurado una periferia urbana dispersa y fragmentada.

Palabras clave: dispersión urbana, desarrollo periférico, expansión urbana, Madrid Bloque temático: morfologías urbanas

\begin{abstract}
Greater Madrid has grown exponentially during the last decades, generating an urban fabric composed by residential, commercial and logistical areas that are dispersed and consume a large amount of resources and soil. This is the basis for establishing that part of Madrid can be studied as a dispersed city, although it is generally perceived as a traditional, compact and dense European city. In this way, Madrid is presented as the ideal laboratory to study the complexity of urban processes conditioned by different urban policies. Thus, we present an image of the current city and the factors that have led it to become a dispersed and fragmented model, and for this we analyze the urban developments framed in the North and South crowns of Madrid: Arroyo del Fresno, Montecarmelo, Las Tablas, Sanchinarro, Valdebebas, and the expansions of Carabanchel and Vallecas.
\end{abstract}

Keywords: urban Sprawl, peripheral development, urban expansion, Madrid Topic: Urban morphologies.

\footnotetext{
${ }^{1}$ Esta ponencia parte de la tesis doctoral de la autora (en curso) titulada igual que la ponencia.
} 


\section{Introducción}

Las políticas urbanas que han configurado la periferia de Madrid han generado un modelo urbano disperso y carente de complejidad que, más que contribuir a la mejora de la calidad de vida urbana y a las necesidades de vivienda de la población, responde a los intereses de sectores inmobiliarios y económicos.

En esta ponencia se presenta de manera resumida un análisis crítico de la situación actual de la periferia de la ciudad de Madrid, haciendo hincapié en cuáles han sido los factores determinantes de su conformación actual a partir del planeamiento reciente, para demostrar que, a pesar de sus diferencias con el modelo de suburbio norteamericano, el modelo de estas periferias puede definirse como urban sprawl.

El objeto de estudio es el desarrollo de siete grandes actuaciones urbanas de la ciudad de Madrid ubicadas tanto en la Corona Norte: Arroyo del Fresno, Montecarmelo, Las Tablas, Sanchinarro y Valdebebas; como en la Corona Sur: Ensanches de Carabanchel y Vallecas, por ser los que configuran la periferia más reciente del Municipio y la que presentan las características del modelo disperso aquí estudiado.

El análisis de los $\mathrm{PAU}^{2}$ se ha realizado a partir de dos herramientas: trabajo de campo y análisis crítico de los Planes Generales de 1985 y 1997 que dan origen a los Planes Parciales, también estudiados, y su manifestación en el territorio, para determinar cómo las políticas urbanísticas y de diseño urbano han conducido a la periferia del municipio hacia un modelo disperso, fragmentado, y carente de la complejidad característica de la una ciudad.

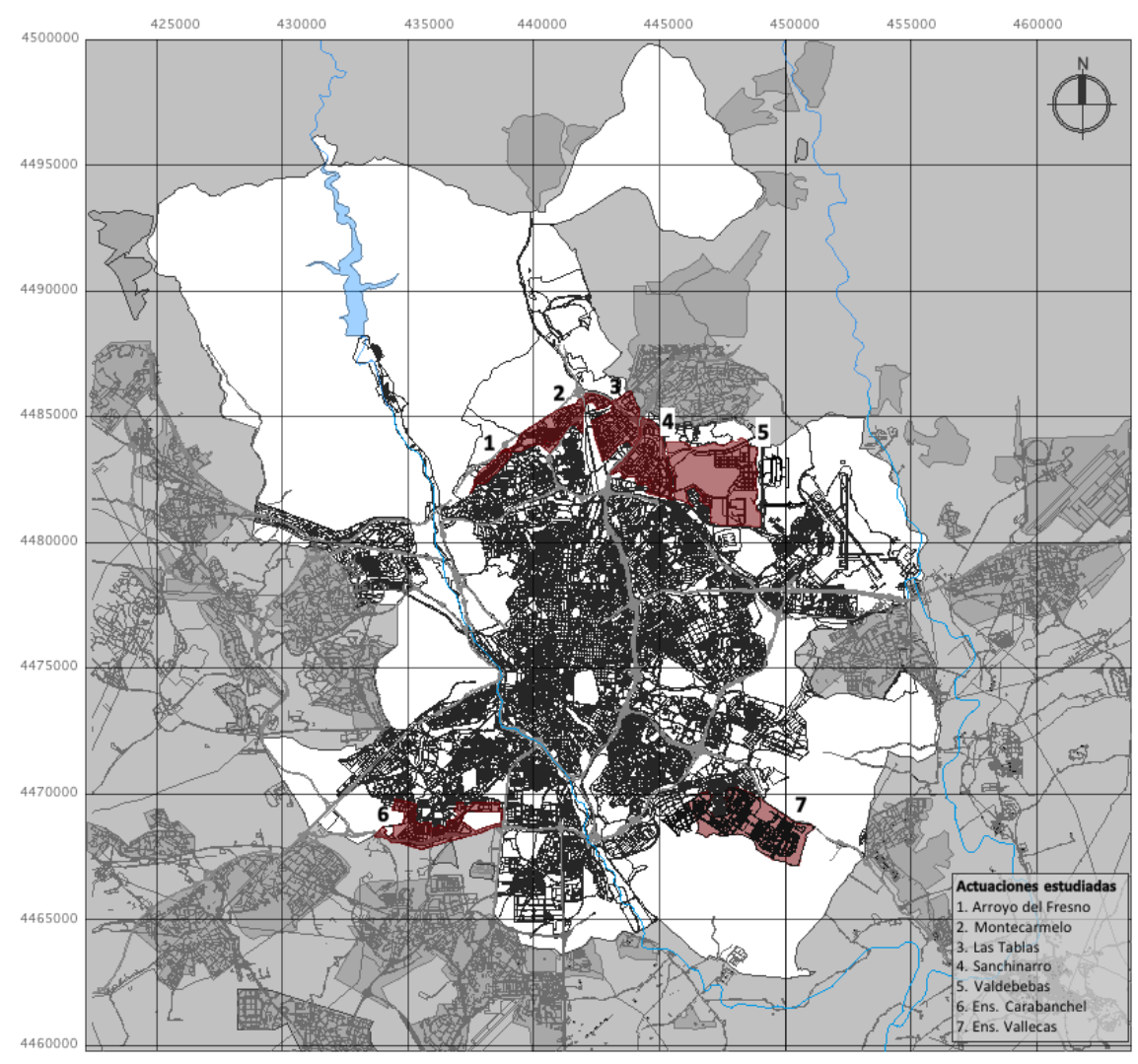

Figura 1. Localización de las actuaciones.

2 La Ley del Suelo de 2001 define la figura del Plan de Actuación Urbanística (PAU) como aquel que desarrolla el Suelo Urbanizable No Programado. EI PAU define el Programa por el que dicho suelo se incorpora al desarrollo de la ciudad, así como su división en sectores y las condiciones de uso y edificabilidad de dichos sectores, que posteriormente habrán de desarrollarse por planes parciales. EI PAU se divide en etapas, sobre las que los correspondientes Planes Parciales fijarán las determinaciones que corresponden a este nivel de planeamiento2. 


\section{Modelo de dispersión urbana.}

A partir de una revisión bibliográfica, se afirma que no existe una única definición del concepto de Dispersión Urbana, pero, por lo general, suele asociarse a un alto consumo de suelo que no responde a las tendencias de crecimiento poblacional. Es un patrón de desarrollo urbano relacionado con el modelo del suburbio norteamericano, conocido como Urban Sprawl. ${ }^{3}$

La Dispersión Urbana puede ser estudiada desde diferentes perspectivas: por sus causas y efectos, por sus costos o impactos sobre el territorio o por su morfología.

Se han planteado ocho dimensiones para medir la dispersión urbana desde el punto de vista del uso del suelo, tomando como parámetros básicos la densidad de los asentamientos y la configuración física de los mismos, en el que un tejido se considera disperso en la medida en que se conjuguen en rangos bajos algunos de los siguientes elementos (Galster et al. (2001):

- Densidad: Promedio de viviendas por superficie de suelo urbanizable.

- Continuidad: Grado en que el suelo urbanizable se ha edificado de manera ininterrumpida.

- Concentración: Grado en que los usos del suelo están distribuidos de forma desproporcionada en relativamente pocos kilómetros cuadrados de la zona urbana total, en lugar que de forma uniforme.

- Agrupamiento: Grado en que los usos del suelo han sido agrupados para minimizar la cantidad de suelo ocupado.

- Centralidad: Grado en que el desarrollo residencial y/o no residencial se encuentra cerca de un distrito financiero.

- Nuclearidad: Grado en que un área se caracteriza por un patrón de desarrollo mononuclear.

- Mezcla de Usos: Grado en que los múltiples usos del suelo coexisten dentro de una misma área, y el hecho de que esto sea común en toda la zona urbana.

- Proximidad: Grado en que los diferentes usos del suelo están cerca uno del otro.

Dependiendo de cómo se combinen estos parámetros, se presenta un tipo u otro de dispersión, pudiendo ser un desarrollo de baja densidad, de tipo lineal o en faja, disperso o de baja continuidad o "salto de rana".

${ }^{3}$ El Urban Sprawl va más allá de la tipología residencial unifamiliar en las afueras de las ciudades, para ser definido debe de incluir parámetros como la mezcla de usos y su distribución por el territorio, la proximidad que existe entre ellos y la manera en que estos se concentran o dispersan. 


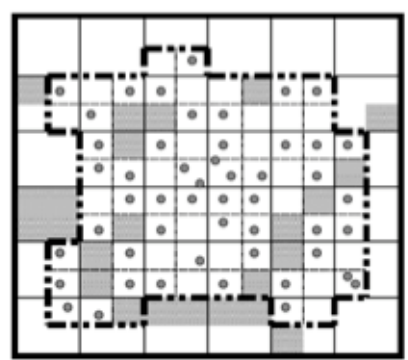

Desarrollo de baja Densidad

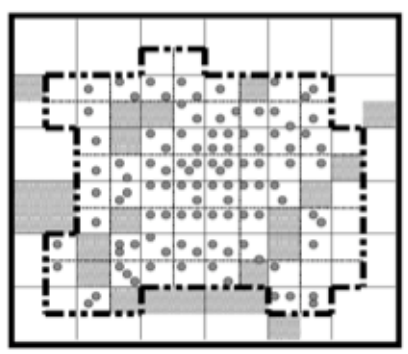

Desarrollo disperso

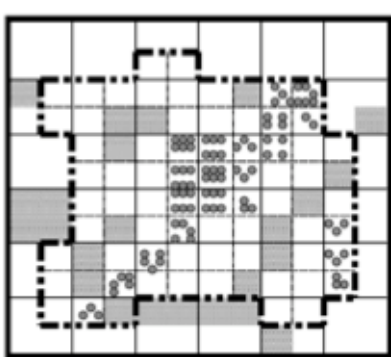

Desarrollo lineal o en faja

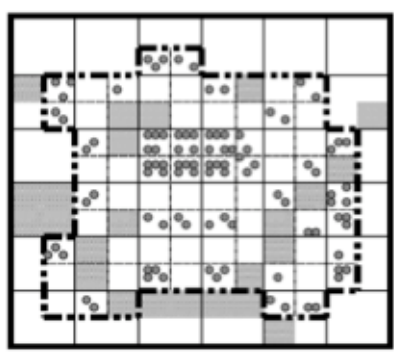

Baja Continuidad. Crecimiento tipo "salto de rana"

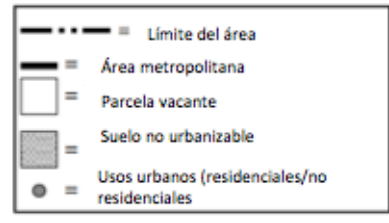

Figura 2. Dimensión morfológica del modelo suburbano. Fuente: Galster et al. (2001).

Para los términos de esta ponencia se define la dispersión urbana como un modelo de expansión urbana caracterizado por la combinación de algunos de los siguientes factores ${ }^{4}$ :

"Densidad de población decreciente acompañada de un mayor consumo de suelo; peso creciente de las zonas periféricas respecto a las centrales; mayor aislamiento (falta de proximidad) entre cada una de las partes de la ciudad, menor concentración de la población en un número limitado de zonas densas y compactas; y una creciente fragmentación del territorio." (Muñiz, García, Calatayud, 2006:5)

Si bien, "el predominio de las bajas densidades tanto en áreas residenciales de vivienda unifamiliar como en las agrupaciones de vivienda colectiva apoyadas en diversos sistemas de infraestructuras viarias y dotadas de extensos espacios libres está en la base del fenómeno de la dispersión urbana (...) este fenómeno va asociado también a la descentralización y al carácter cada vez más extensivo de las nuevas áreas industriales, los parques vallados de oficinas, los equipamientos deportivos (...) universidades, aeropuertos e implantaciones civiles o militares, centros comerciales, instalaciones técnicas cada vez más devoradoras de espacio. (...) piezas cada vez más autónomas que se yuxtaponen en forma discontinua y entre las cuales proliferan espacios intersticiales que producen un efecto final de descenso generalizado de las densidades brutas" (Monclús, 1998:7).

\section{El planeamiento reciente y su relación con la periferia.}

Los Planes de Ordenación de Madrid recientes han sido determinantes en la configuración de las periferias. Sus planteamientos, enmarcados dentro de las realidades socioeconómicas del momento, han sido por lo general contradictorios.

El Plan General de Ordenación Urbana de Madrid, en adelante PGOUM85, planteó aprovechar la oportunidad que brindaban los vacíos resultantes del crecimiento "a saltos" y los generados por el suelo calificado como rústico-forestales (anillos verdes) para rematar y terminar una ciudad que describieron como inacabada, buscando esponjar el centro consolidado, y dotarlo de espacios públicos y equipamientos (Ayuntamiento de

${ }^{4}$ Se ha optado por esta definición porque sintetiza de manera operativa los parámetros que la mayoría de los autores consultados han utilizado para definir el concepto de dispersión urbana. 
Madrid, 1982). Esta decisión fue determinante a la hora de plantear cómo y de qué dimensiones serían los nuevos crecimientos propuestos

EI PGOUM85 buscaba ordenar lo existente, recuperando el Centro y estableciendo un principio de austeridad urbana, implementando una estrategia de acupuntura urbana en vez de grandes actuaciones urbanísticas. También planteó descongestionar el Centro de ciertas actividades, y fomentando también el uso residencial; de esta manera nace la idea de los ensanches recientes, denominados PAU.

En cambio, el Plan General de Ordenación Urbana de 1997, en adelante PGOUM97 buscaba proyectar una ciudad con miras al siglo XXI, a través de un conjunto de políticas dinamizadoras de la actividad urbana, planteando estrategias como el planeamiento al limite de la capacidad y la difusión de la centralidad a través de la creación de nuevas centralidades en áreas vacantes, para remediar los desequilibrios territoriales heredados. Dentro de este contexto se asumen y modifican los PAU que no se llegaron a concretar en el Plan anterior, y se suman otros desarrollos que completan el término municipal.

De esta manera, los PAU planteados originalmente en el PGOUM85, pasan a asumirse dentro del PGOUM975. Sin embargo, en el desarrollo de los Planes Parciales de las actuaciones es posible constatar que estos no tienen nada que ver con lo que originalmente se planteó en el PGOUM85, ni en escala ni en su relación con la ciudad preexistente.
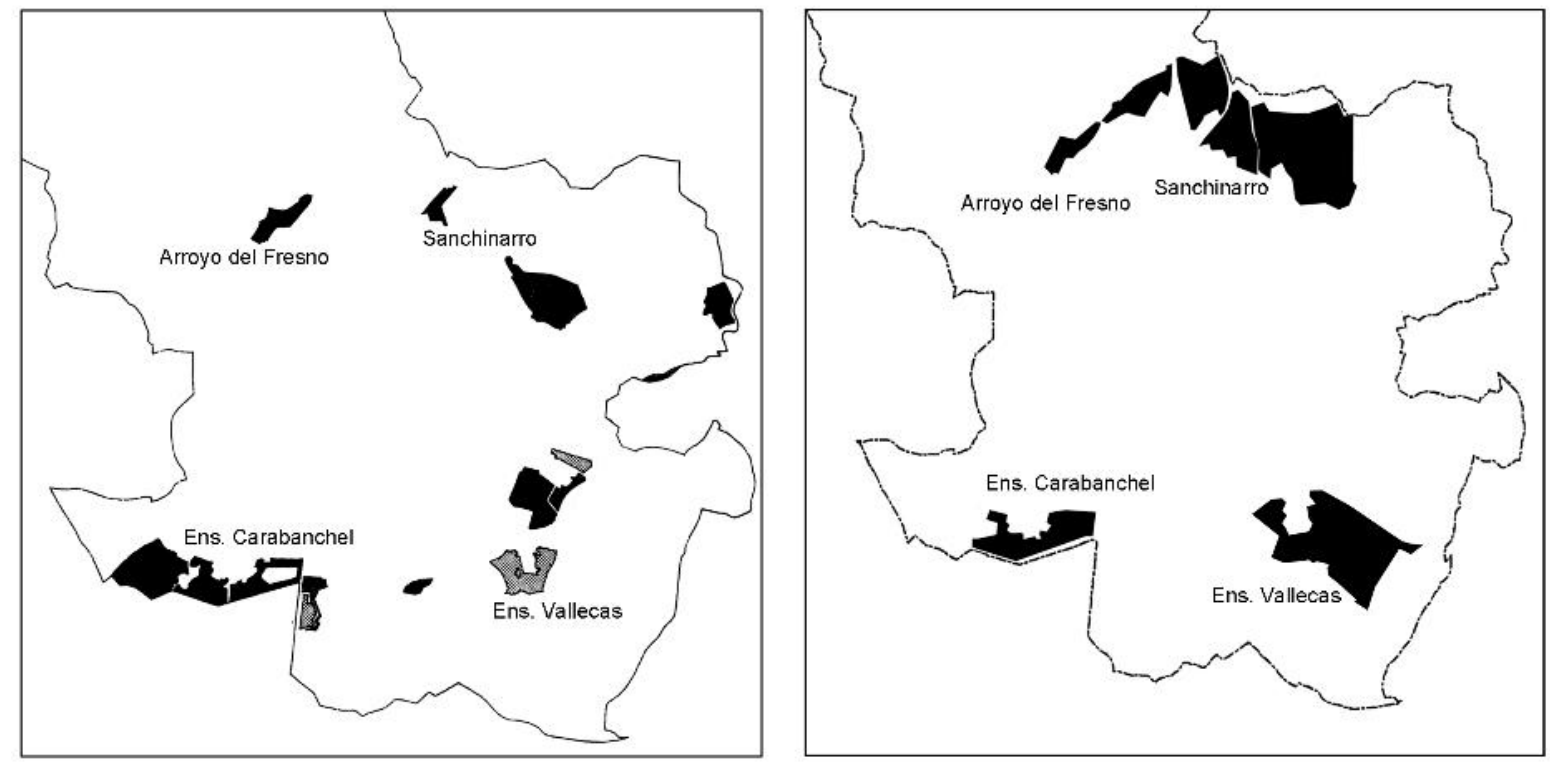

Figura 3. Comparativa entre los Nuevos desarrollos de Vivienda planteados por el PGOUM85 y los planteados por el PGOUM97. En esta se puede observar cómo cambia la escala. También se puede ver que solo arroyo del Fresno y el Ensanche de Carabanchel conservan el tamaño original, mientras que Sanchinarro es ampliado considerablemente.

\footnotetext{
${ }^{5}$ A pesar de que las actuaciones estudiadas se llevaron a cabo a partir de la aprobación del PGOUM 97, todas, salvo Valdebebas, venían contemplados en el PGOUM85 y en sus modificaciones en junio de 1992, bajo la denominación de programas de actuación urbanística (PAU) como parte de las previsiones de suelo para la construcción de viviendas. En el PGOUM97 aparecen como actuaciones en Suelo Urbanizable Incorporado, Urbanizable Programado y Urbanizable No Programado. En esta ponencia seguimos refiriéndonos a ellos como PAU por ser la forma más utilizada para referirse a estos en relación a su origen en el PGOUM85.
} 


\section{La periferia reciente}

\subsection{Tamaño, densidad y uso de suelo.}

Las actuaciones ocupan una superficie bruta de 3.292,68 hectáreas y contemplan la construcción de 90.569 viviendas. Si a esto restamos las áreas verdes, que en algunos casos son de escala metropolitana, hablamos de una superficie neta de 2.052,22 ha, es decir unas cuatro veces el tamaño de la almendra central de Madrid, pero con una densidad residencial que representa aproximadamente solo una tercera parte de esta.

Tanto la distribución de las viviendas como de la superficie de las actuaciones es bastante heterogénea, pues van desde las 148,65 hasta las 1.064,9 hectáreas y desde las 3.240 hasta las 28,058 viviendas.

A pesar de estas diferencias, las densidades brutas son bastantes similares, pues van desde las 33,41 viv/ha hasta las 39,10 viv/ha. Esto no ocurre en el caso de Arroyo del Fresno con una densidad bruta de 21,80 viv/ha, ni en el caso de Valdebebas, que aún restando el parque metropolitano, la densidad bruta es de 21,35 viv/ha.

Como el objetivo principal de las actuaciones es el de ofrecer vivienda asequible, su vocación es residencial. Sin embargo, también se plantean usos complementarios que potencien su objetivo de convertirse en centralidades y subsanen los desequilibrios dotacionales que derivan en dependencia periferia-centro, por ellos se plantean usos terciarios-comerciales y dotacionales en todos los PAU, e industriales en Sanchinarro, Carabanchel y Vallecas. Sin embargo, más del 75\% del uso industrial se concentra en estos dos últimos, lo que de cierta manera refuerza el desequilibrio existente en Madrid, donde la industria se concentra al sur.

Arroyo del Fresno, Montecarmelo y Vallecas contemplan viviendas unifamiliares. Estas representan entre un 23-30 \% de la oferta de suelo residencial de dichas actuaciones, y un 11,65\% del total del suelo residencial de las siete actuaciones analizadas. En todos los casos las manzanas destinadas a viviendas unifamiliares se encuentran agrupadas en zonas limítrofes, de forma que no se mezclan con las viviendas colectivas.

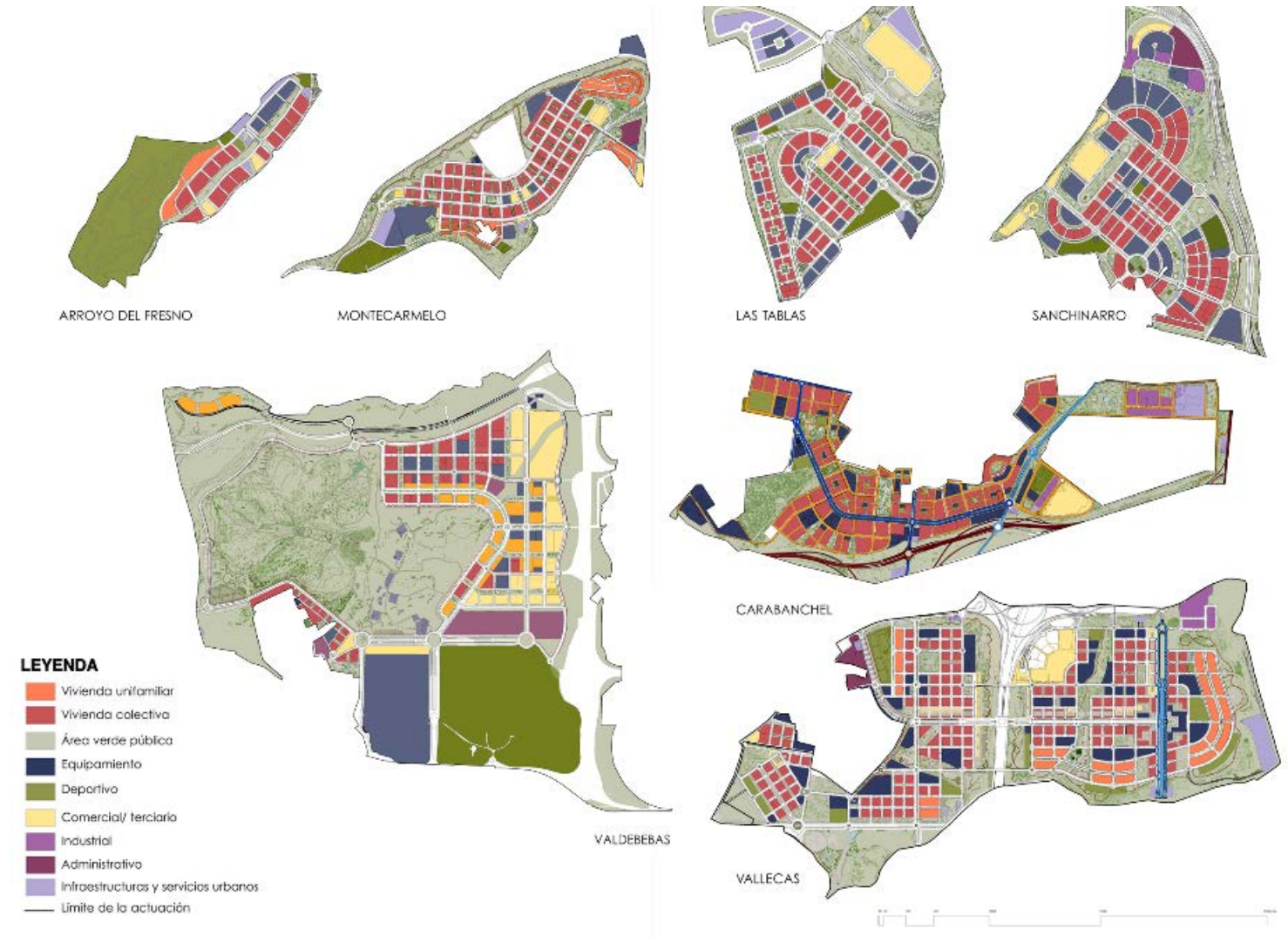

Figura 4. Planos de Calificación. 
Las densidades son notablemente bajas al ser comparadas con los ensanches del PGOUM85 que manejaban densidades de entre 60-90 viv/ha, pues hablamos de una densidad promedio de 30,23 viv/ha. Incluso si se restan las áreas verdes, la densidad no superaría las 45 viv/ha, es decir, las mínimas recomendable para la existencia de vida urbana ${ }^{6}$.

Montecarmelo, Sanchinarro, Valdebebas, Ensanche de Carabanchel y Ensanche de Vallecas tienen un centro comercial, lo que dificulta el desarrollo del pequeño comercio, que se ve absorbido por la influencia del mismo. El comercio en planta baja suele ubicarse en las vías principales de las actuaciones, por lo que las demás vías pierden parte de la actividad cotidiana que hace rica la vida urbana.

\subsection{Estructura urbana.}

La forma de los PAU se relaciona directamente con las autopistas y vías de circunvalación limítrofes, y en menos medida con el territorio y el contexto urbano. Esto se puede constatar al analizar la dirección que toman las vías internas de las actuaciones, que responden por lo general a los ejes principales externos a la actuación, o a las formas poco ortogonales que toman algunas manzanas que responden a las formas singulares de las actuaciones.

Las formas singulares de los PAU vienen determinadas por ser el "relleno" de los vacíos urbanos generados entre la M-40, la M-50 y la ciudad consolidada en un intento de remate de la ciudad.

En teoría, los PAU forman parte de las propuestas para articular y equilibrar la ciudad existente, pero ellos en sí mismos no parecen formar parte del sistema urbano consolidado, sino piezas anexas a la ciudad. Esto debido a la fragmentación y la falta de proximidad que existe entre las actuaciones y su contexto generada por las grandes infraestructuras viales, franjas de protección y áreas verdes.

Según el PGOUM97, las actuaciones de la Corona Norte debían de leerse como una simbiosis de operaciones urbanísticas, donde se interpondrían dos mallas yuxtapuestas, una la red viaria y la otra el sistema de espacios libres y dotacionales, garantizando la conectividad y permeabilidad del conjunto. Sin embargo esto se ha quedado en intenciones, pues las mismas infraestructuras que dan forma a las actuaciones también las fragmentan.

En el PAU de Vallecas por ejemplo, la fragmentación provocada por autopistas es más evidente, pues la M-45 lo parte en dos: con cinco carriles de circulación y dos carriles de acceso en cada sentido, sumados a las franjas verdes de protección, crean una barrera de 500 metros entre ambos lados del PAU.
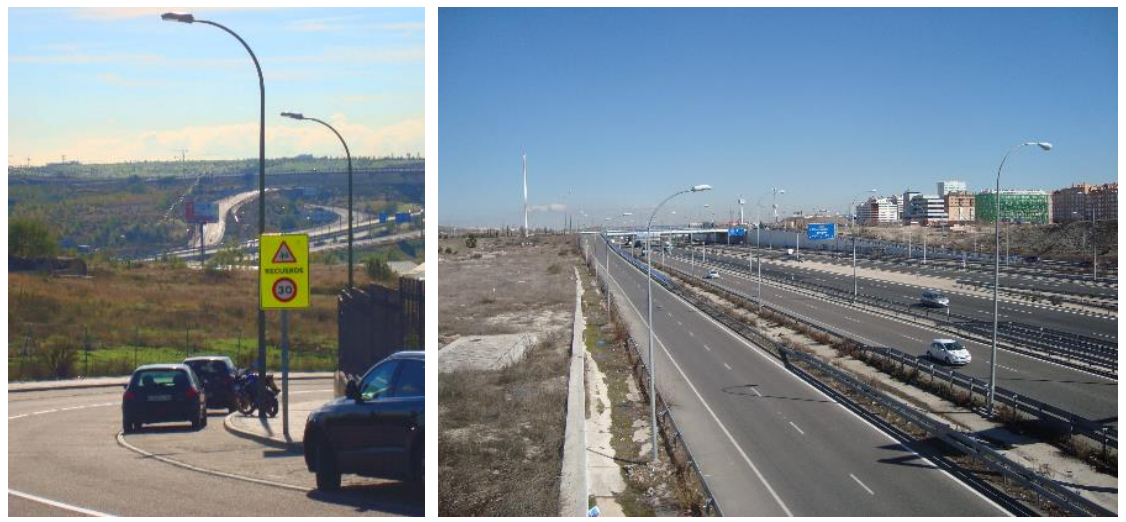

Figura 5. Autopista A1 y su franja de protección vista desde Sanchinarro (izq). M-45 vista desde el Ens. De Vallecas (der). En estas imagines se puede percibir la gran frangmentación que provocan las vías de comunicación y sus respectivas franjas de protección en las actuaciones. Fuente: Propia

\footnotetext{
${ }^{6}$ López de Lucio (2007) subraya que unas densidades medias del orden de 45-50 viviendas/ha serian las densidades mínimas recomendables para permitir concentraciones o nodos de urbanidad, pudiendo ascender estas a entornos de $75-85$ viviendas/ha o incluso superiores.
} 
Las infraestructuras ferroviarias también ejercen como barreras entre los barrios: Montecarmelo se encuentra separado de Las Tablas; Las Tablas de Tres Olivos, y ambas a su vez del Casco histórico de Fuencarral, es decir de la ciudad consolidada a la que pretenden rematar.

\subsection{Trama viaria.}

La manera en que se han insertado las actuaciones divididas por grandes infraestructuras viales ha generado un evidente aislamiento entre los nuevos tejidos y la ciudad consolidada, lo cual provoca una marcada discontinuidad.

Las vías de comunicación condicionan, en la mayoría de los casos, la composición de las vías interiores de las actuaciones, así como también la orientación de las manzanas. Por lo general se ha decidido partir de alguno de los ejes viarios que bordea las actuaciones para generar una trama urbana ortogonal. En otros casos se ha proyectado una vía principal distrital, que es la que comunica la actuación con los barrios colindantes, y a partir de esta se ha generado la trama.

A pesar de que en todos los casos se opta por la tradicional malla ortogonal, no siempre ha mantenido la regularidad de los ensanches clásicos, pues en ocasiones se ha optado por líneas curvadas y fragmentos de retículas.

Una condición latente en la mayoría de los PAU es que no continúan con la trama existente, sino que plantean su propia estructura, que en algunos casos rompe totalmente con su entorno, dificultando la relación entre los nuevos crecimientos y la ciudad consolidada.
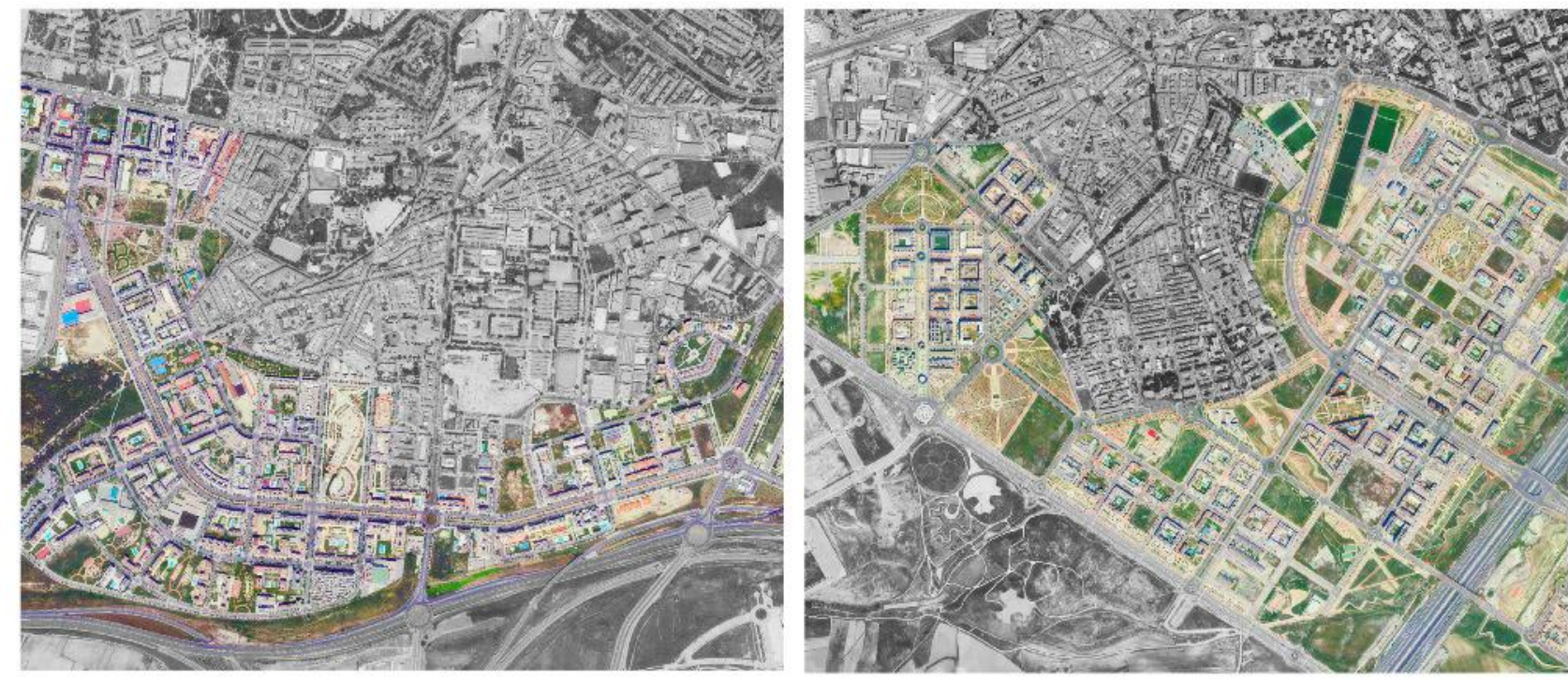

Figura 6. Parte más próxima de los Ensanches de Carabanchel (izq) y Vallecas (der) a su Casco Histórico. En estas imagines se puede contrastar la forma en la que En Carabanchel se hace un esfuerzo por continuar la trama existente, mientras que en Vallecas se ignora totalmente y se plante una trama que nada tiene que ver con el contexto. Fuente: Google maps.

\subsection{Morfología y tipología.}

La manzana tipo en los PAU es rectangular o cuadrada con superficies bastantes distintas, pues en un mismo PAU podemos encontrar tanto manzanas de $2,700 \mathrm{~m}^{2}$ como manzanas de $15.900 \mathrm{~m}^{2}$.

La conformación de las manzanas varía en función del tipo edificatorio, pero las dos tipologías principales son las de manzana cerrada de vivienda colectiva con un único bloque continuo que bordea toda la parcela con patio interior y las de manzana semi-cerradas con varios bloques de vivienda colectiva con área privada. 
Montecarmelo, el Ensanche de Carabanchel y el Ensanche de Vallecas poseen manzanas compuestas por dos parcelas de bloques continuos o semi-cerrados con una franja o área verde pública en el centro. En Las Tablas y en el Ensanche de Carabanchel aparece la agrupación de cuatro manzanas (cerradas o semicerradas) con una parcela central que puede ser un parque, un equipamiento o la combinación de ambos.
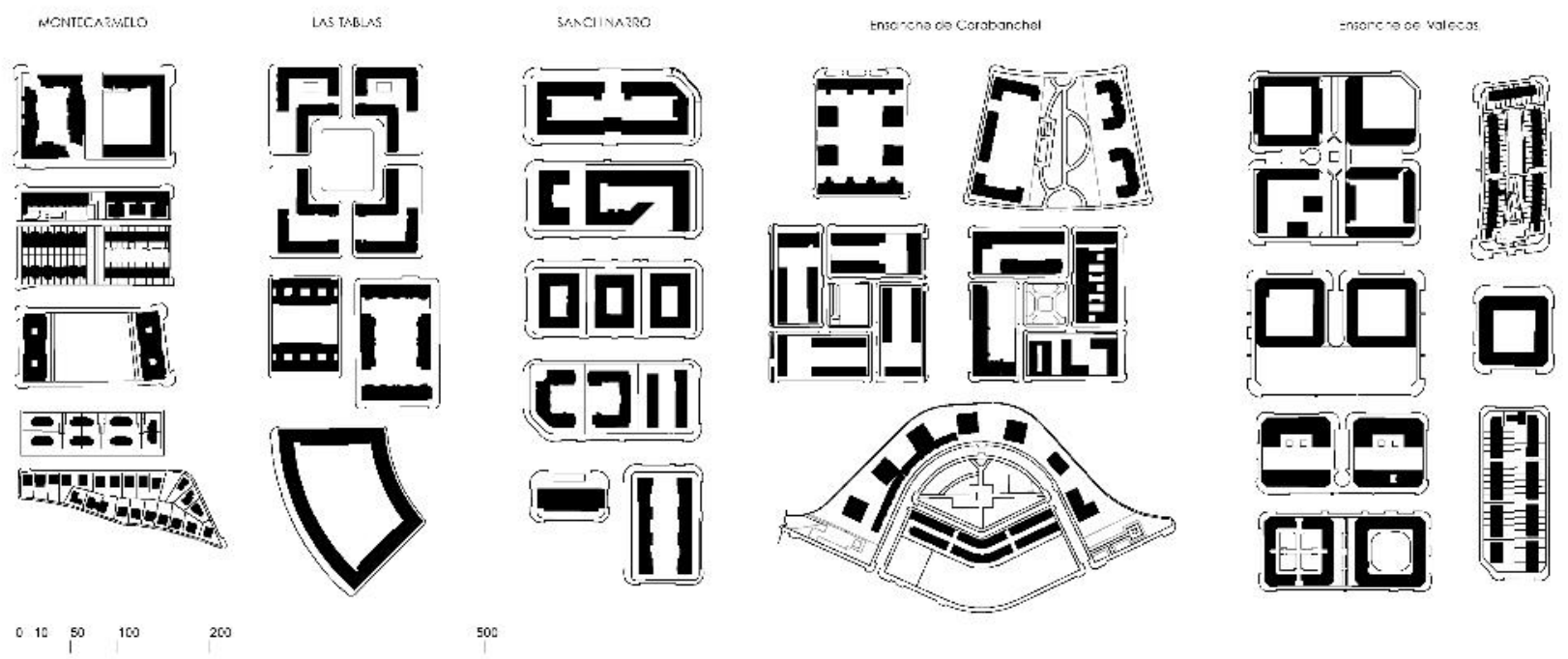

Figura 7. Análisis morfológico de las principales tipologías de manzanas . Fuente: Elaboración propia.
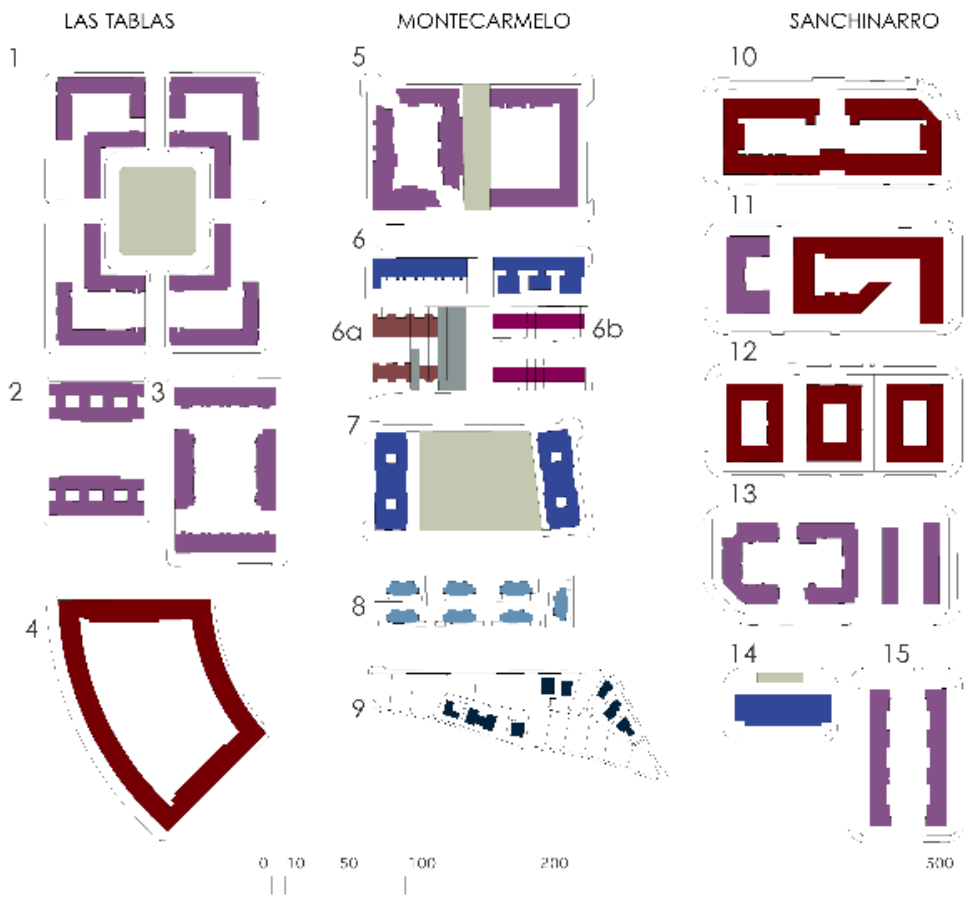

Tipología de manzanas.

1. Macro-manzana: cuatro manzanas semi-cerradas de bloques de vivienda con un parque o plaza central de uso público. manzanas principales

2-3-11-15. Manzana semi-cerrada: de bloques lineales con espacio libre privado comunitario.

4-10. Manzana cerrada: bloque lineal de frente continuo con espacio central libre comunitario.

5. Manzana compuesta: dos semi-manzanas y franja libre pública entre ellas.

6. Semi manzana: bloques lineales de vivienda colectiva y espacio libre público entre los bloques.

Semi manzana compuesta por viviendas unifamiliares en hilera (6a) y en hilera con espacio libre privado comunitario (6b)

7. Manzana compuesta por dos parcelas de bloques lineales de uso mixto en altura y un área libre pública que las separa.

8. Zona residencial unifamiliar aislada, viviendas unifamiliares pareadas.

9. Manzana de viviendas unifamiliares en parcela exenta.

12. Manzana de tres parcelas cerradas de bloques de vivienda colectiva con espacio privado comunitario y viviendas en los bajos.

13. Manzana de tres parcelas semi-cerradas de bloques de vivienda colectiva con espacio privado comunitario.

Figura 8. Análisis tipología de manzanas según el tipo edificatorio. Fuente: Elaboración propia 


\section{Modelo adoptado y el fracaso de dicha fórmula.}

\subsection{Crecimiento desmesurado.}

Una de las características fundamentales del proyecto de futuro del PGOUM97 ha sido la del planeamiento al límite de la capacidad. Para ello se recalifica una cantidad de suelo "suficiente" para hacer frente a las necesidades de vivienda del municipio de Madrid, ya que ampliar la oferta de suelo urbanizable abarataría los costos del mismo y por ende de la vivienda.

Sin embargo, "en general, el precio de la vivienda lo fija el mercado, y no sólo ni necesariamente por la demanda de alojamiento, y es el precio de esta el que permite pagar más o menos por el suelo" (Vinuesa et. al., 2013).

El PGOUM97 asume que la sola calificación de suelo no era suficiente, por lo que era necesario que se desarrollara una "gestión ágil y eficaz de lo planificado" si se quería "disponer de un stock suficiente de suelo en el mercado, con el objetivo de paliar los efectos negativos de los procesos especulativos y alzas bruscas de precio" (Ayuntamiento de Madrid, 1997), pero ha quedado demostrado durante lo acontecido en las últimas décadas, que no han podido frenarse los procesos especulativos de la vivienda.

Fomentar el crecimiento hasta el limite sin establecer una lógica de crecimiento dificulta el crecimiento razonable, pues a pesar de que se ha incrementado la oferta de vivienda asequible, no se han tomado en cuenta los costes adicionales (sobre todo en transporte) en los que se debe incurrir al vivir en una periferia que no cuenta con todas las funciones propias de una ciudad.

La urgencia por desarrollar suelo para dar accesibilidad a vivienda barata se ha convertido en un despilfarro de recursos que ha traído como consecuencia un modelo de crecimiento desmesurado e injustificado ${ }^{7}$, que no se ha programado en sintonía con la demanda real y la previsión de crecimiento de la población y "nos lleva a pensar que la autentica motivación, la única que realmente puede explicar tan desproporcionadas propuestas de crecimiento urbano de Madrid, es la generación de inmensas plusvalías en forma casi automática (...) y la perspectiva de dinamizar con ello, en el corto plazo, la actividad económica mediante la urbanización y la construcción" (Vinuesa et. al., 2013).

\subsection{Poca complejidad.}

Una de las cuestiones claves en el fracaso del modelo urbano de los PAU ha sido proponer densidades residenciales bajas, que según el PGOUM97 "rozaría el nivel mínimo para conseguirla tensión urbana imprescindibles para conseguir auténticos barrios con vida social" (Ayuntamiento de Madrid, 1997:154). Sin embargo, las densidades propuestas no son suficientes para conseguir dicha tensión urbana. Indudablemente solo se ha pensado en preparar suelo para ampliar la de oferta de vivienda, pero no en la manera de optimizar el consumo y uso del suelo.

Debido a la disposición de los usos no residenciales, se ha perdido completamente el concepto de mezcla de uso, pues la mayoría de las edificaciones no posee bajos comerciales y los usos terciarios y dotacionales se concentran en manzanas agrupadas en los extremos de las actuaciones.

El modelo de la ciudad tradicional, caracterizada por su intensa vida urbana, tiene como distintivo el hecho de distribuir la actividad comercial a lo largo de vías principales y secundarias. La concentración de actividades

\footnotetext{
${ }^{7}$ Durante el periodo 2010-2020 el saldo entre la estimación de oferta de vivienda -por el conjunto de los PAU y las demás grandes actuaciones propuestas por el PGOUM97- y la estimación de demanda refleja un excedente de, aproximadamente, 128.000 viviendas, en el conjunto del Municipio. El tiempo necesario para agotar esa capacidad de nuevas viviendas rondaría el medio siglo (Vinuesa et. al., 2013).
} 
en grandes superficies es posterior, y sin embargo, en la ciudad tradicional conviven ambas tipologías en armonía, complejizado la forma de usar la ciudad, cosa que no ocurre en los PAU.

La localización periférica de equipamientos y zonas verdes, sumado a la dispersión del tejido residencial y la baja densidad, dificultan la interacción e integración social, elementos que juegan a favor de la cohesión social. Esta disposición de los usos de suelo condena a los residentes a vivir en situaciones deficitarias en servicios y animación urbana, obligándolos a desplazarse largas distancias para acceder a estos.

\subsection{Dependencia del automóvil.}

Una de las exigencias de cualquier nuevo desarrollo urbanístico es la coordinación entre planeamiento y transporte público, y para ello ha de tomarse en cuenta que el uso efectivo del mismo se ve afectado directamente por la baja densidad y la carencia de complejidad.

Para garantizar la viabilidad económica del transporte público es necesario fijar densidades edificatorias mínimas entre 60-70 viv/ha, que es el doble de la densidad existente en los PAU. Asimismo, es necesaria la localización de las actividades que mayor movilidad generan junto a los modos de transporte público (Irastorza, 2012).

A partir de estos datos se puede afirmar que a pesar de que las actuaciones tienen acceso al transporte público, la cantidad de usuarios es insuficiente para hacerlos eficientes, y se recurra al uso del automóvil. Además, aparentemente no se contempló el uso de la bicicleta como alternativa al coche, pues los carriles bici se han diseñado sólo con carácter lúdico.

\subsection{Homogeneidad.}

La marcada homogeneidad socioeconómica en los PAU se evidencia en la mono funcionalidad y en la segregación social y generacional existente, debido en parte a la poca diversidad tanto en el parque de viviendas como de rentas.

La disposición de las viviendas condiciona la poca mezcla de diversidad social, pues las viviendas con algún régimen de protección suelen ubicarse en terrenos menos atractivos, como cerca de la vías del tren o en las áreas más periféricas, mientras que las viviendas libres ocupan localizaciones más agraciadas. Esto no genera necesariamente segregación social, pero influye en la forma en que los distintos grupos se relacionan. Las actuaciones representan el $10 \%$ de la población madrileña con un predominio relativo de las nuevas clases medias urbanas. El $60 \%$ de la población está formada por parejas jóvenes con niños con escasa presencia multicultural (Ayuntamiento de Madrid, 2009).

La homogeneidad resultante dificulta la diversidad necesaria para conseguir la complejidad propia de una ciudad y esto se refleja en una imagen monótona con ausencia de señas de identidad, cuyas consecuencias afectan en gran medida a la vida de la calle, limitándola, y reduciendo la presencia comercial (Ayuntamiento de Madrid, 2009).

Una condición necesaria para lograr la animación de la calle es contar con una estructura residencial y de actividades de cierta densidad. Sin embargo, es frecuente constatar que la simplificación de las tipologías de espacios públicos, unida a la carencia de una densidad edificatoria suficiente para garantizar un umbral mínimo de actividad, tienen como consecuencia del abandono de la calle y su transformación en un espacio deteriorado e inseguro (Ezquiaga 2002). 


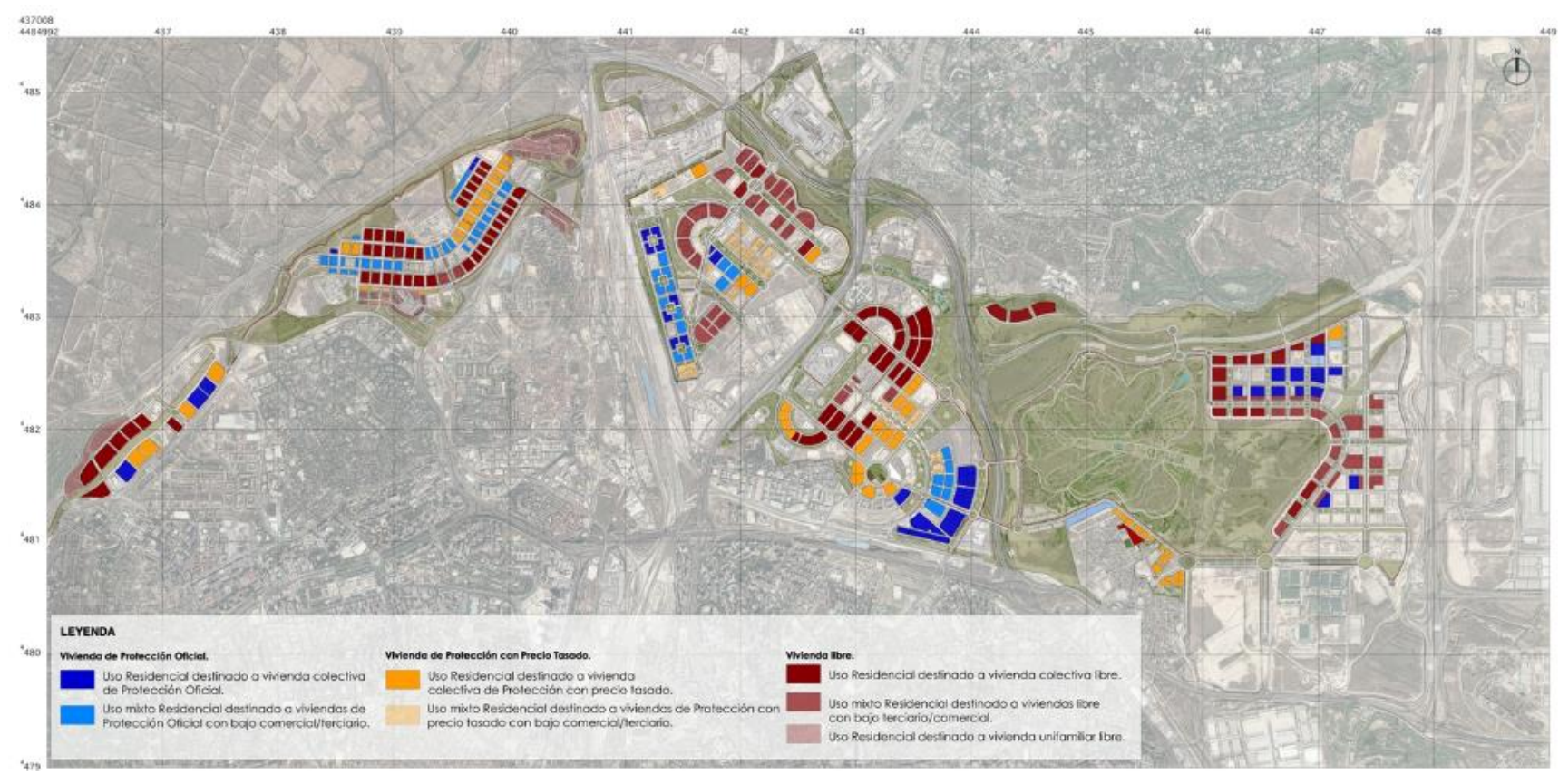

Figura 9. Calificación pormenorizada de usos residenciales. En este mapa pueden observarse varios elementos interesantes. En primer lugar la agrupación de vivienda según su régimen, donde las de protección (tonos de azul) se suelen ubicar en las posiciones menos ventajosas. En Segundo lugar, los bajos comerciales (tonalidades más claras) se alinean en las calles principales.

\subsection{Vida urbana pobre.}

Otro desacierto han sido las manzanas cerradas, pues sus patios de dimensiones excesivas fomentan la vida interior en detrimento de la interacción social en el espacio público, lo que puede reflejarse en que la pérdida del papel de la calle como elemento básico de relación social, pues al perder funciones, que en la ciudad tradicional se suelen dar a pie de calle, se convierten en meros ejes de comunicación vehicular.

Una condición necesaria para lograr la animación de la calle es contar con una estructura residencial y de actividades de cierta densidad, pero la densidad residencial de los PAU no garantiza el umbral mínimo de actividad, generando el abandono de la calle. 

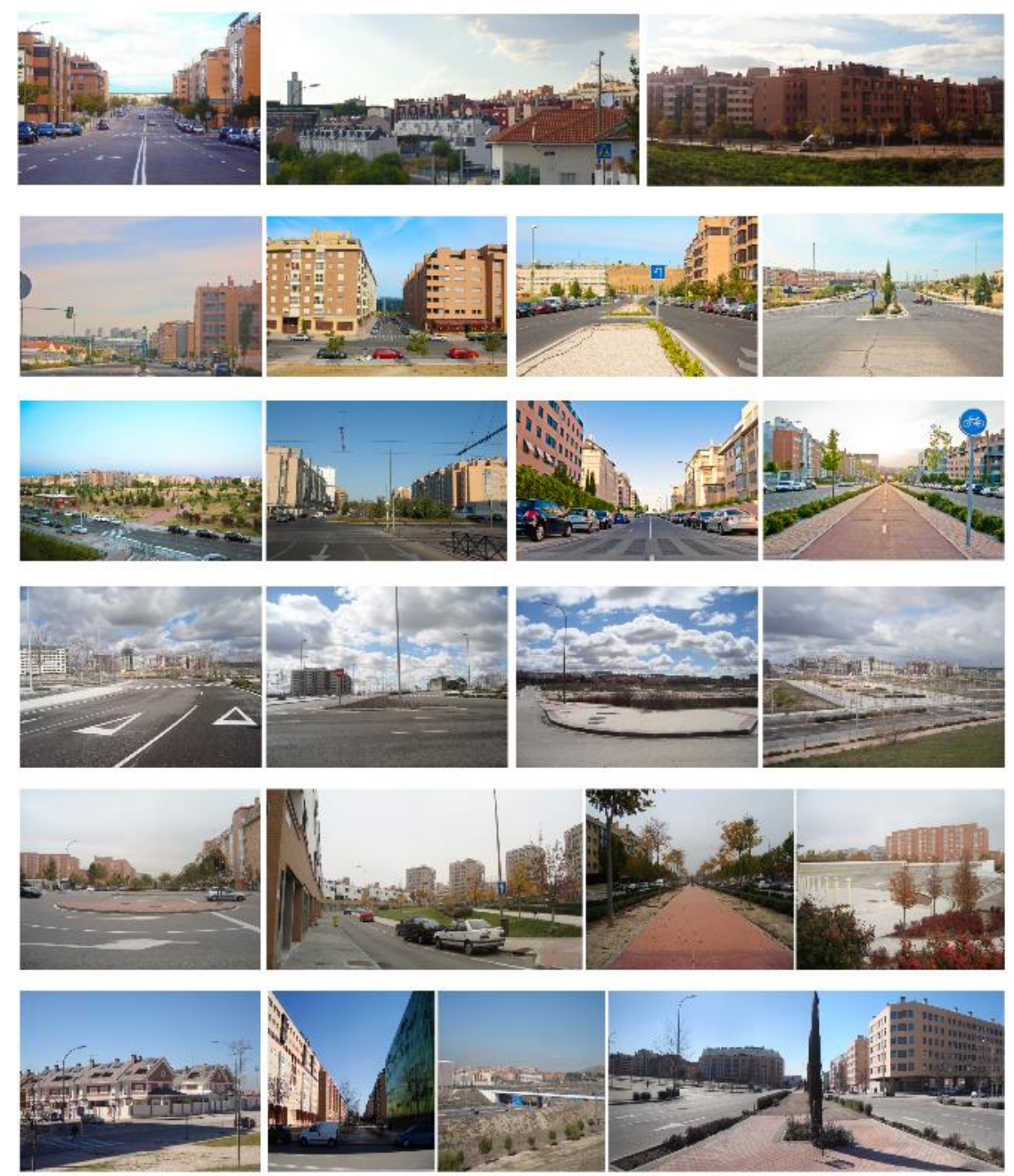

Figura 10. Fotografías de varios PAU. De arriba a abajo: Montecarmelo, Las Tablas, Sanchinarro, Carabanchel y Vallecas. En estas podemos confirmar la gran homogeneidad en la materialidad, tipologías, fachadas y espacio público. Otro aspecto curioso es el hecho de que no aparecen personas en ningunas de las escenas, cosa que no fue planificada por la autora. Fuente: propia.

\subsection{Espacio público desmesurado.}

Las zonas verdes representan más del 25\% la superficie de las actuaciones, es decir una repercusión de más de $80 \mathrm{~m} 2$ de área verde por vivienda o $33 \mathrm{~m} 2 / \mathrm{hab}$, sin contar con los amplios patios de manzanas que pueden ir desde los $2.500 \mathrm{~m} 2$ a los $6.700 \mathrm{~m} 2$. En algunos casos la trama de espacios públicos fragmenta, en vez de integrar.

Estos datos por si solos quizás no sean alarmantes, pero comparados con el Ensanche de Castro, donde los patios de manzana no superaban los $2.000 \mathrm{~m} 2$, o con la superficie de áreas verdes de Madrid Sur (Desarrollado a partir del PGOUM85), que no superaban el $17 \%$ de la superficie total del sector (unos $20 \mathrm{~m} 2$ de suelo por vivienda), y tomando en cuenta que la media municipal de áreas verdes es de $22 \mathrm{~m} 2 / \mathrm{hab}$ y de $10 \mathrm{~m} 2 / \mathrm{hab}$ en la almendra central, notamos que efectivamente se produce un sobre dimensionamiento indiscriminado de áreas libres. 


\begin{tabular}{|c|c|c|c|c|c|c|c|c|c|c|c|}
\hline \multirow[b]{2}{*}{ Actuación Urbanística } & \multirow{2}{*}{$\begin{array}{c}\text { Superficie total } \\
(\mathrm{m} 2)\end{array}$} & \multicolumn{2}{|c|}{ Residencial } & \multicolumn{2}{|c|}{ Ierciario } & \multicolumn{2}{|c|}{ Industrial } & \multicolumn{2}{|c|}{ Zonas verdes (Ha) } & \multicolumn{2}{|c|}{ Dotacional } \\
\hline & & Superficie & $\%$ & Superficie & $\%$ & Superficie & $\%$ & Superficie (m2) & $\%$ & Superficie (m2) & $\%$ \\
\hline UZ1.0.06 Arroyo del Fresno & 1.486 .466 & 271.418 & 18,26 & 19.878 & 1,34 & - & - & 99.000 & 6,66 & $318.044,00$ & 21,40 \\
\hline UZI.0.07 Montecarmelo & 2.558 .000 & 546.815 & 21,38 & 50.498 & 1,97 & - & - & 786.800 & 30,76 & $1.173 .887,00$ & 45,89 \\
\hline UZI.0.08 Las Tablas & 3.623 .000 & 530.768 & 14,65 & 192.100 & 5,30 & - & - & 1.012 .300 & 27,94 & $1.887 .832,00$ & 52,11 \\
\hline UZI.0.09 Sanchinarro & 3.869 .000 & 643.719 & 16,64 & 153.196 & 3,96 & 58.152 & 2 & 1.259 .900 & 32,56 & $1.754 .307,58$ & 45,34 \\
\hline $\begin{array}{l}\text { UNP.4.01 Ciudad Aeroportuaria- } \\
\text { Parque de Valdebebas( }{ }^{*} \text { ) }\end{array}$ & 5.853 .936 & 573.700 & 9,80 & 434.951 & 7,43 & 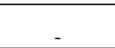 & - & 528.719 & 9,03 & $9.111 .806,00$ & 155,65 \\
\hline UZI.0.10 Ensanche Carabanchel & 3.565 .600 & 661.881 & 18,56 & 45.221 & 1,27 & 125.967 & 4 & 1.405 .100 & 39,41 & $1.327 .433,51$ & 37,23 \\
\hline UZP.1.03 Ensanche Vallecas & 7.175 .700 & 1.026 .652 & 14,31 & 275.676 & 3,84 & 62.724 & 1 & 2.517 .800 & 35,09 & $3.290 .199,60$ & 45,85 \\
\hline IOIAL & $32.926 .766,00$ & $4.254 .952,80$ & 16,23 & $1.171 .519,80$ & 3,59 & $246.843,06$ & 5,91 & $7.609 .619,00$ & 25,92 & $18.863 .509,69$ & 57,64 \\
\hline
\end{tabular}

Tabla 1. Datos urbanísticos básicos de las actuaciones. Fuente: Elaboración propia a partir de las fichas urbanísticas de las actuaciones.
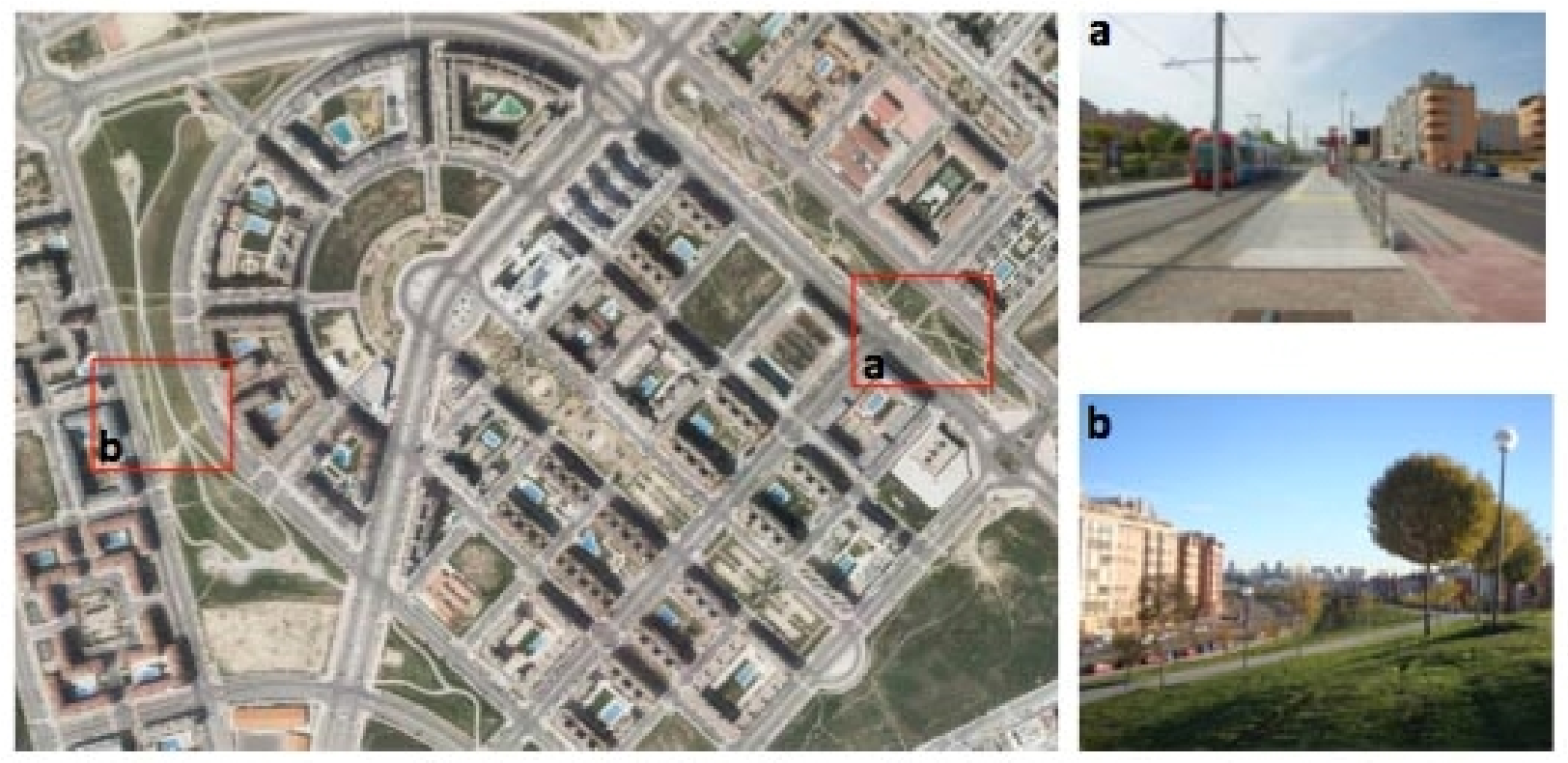

$-$

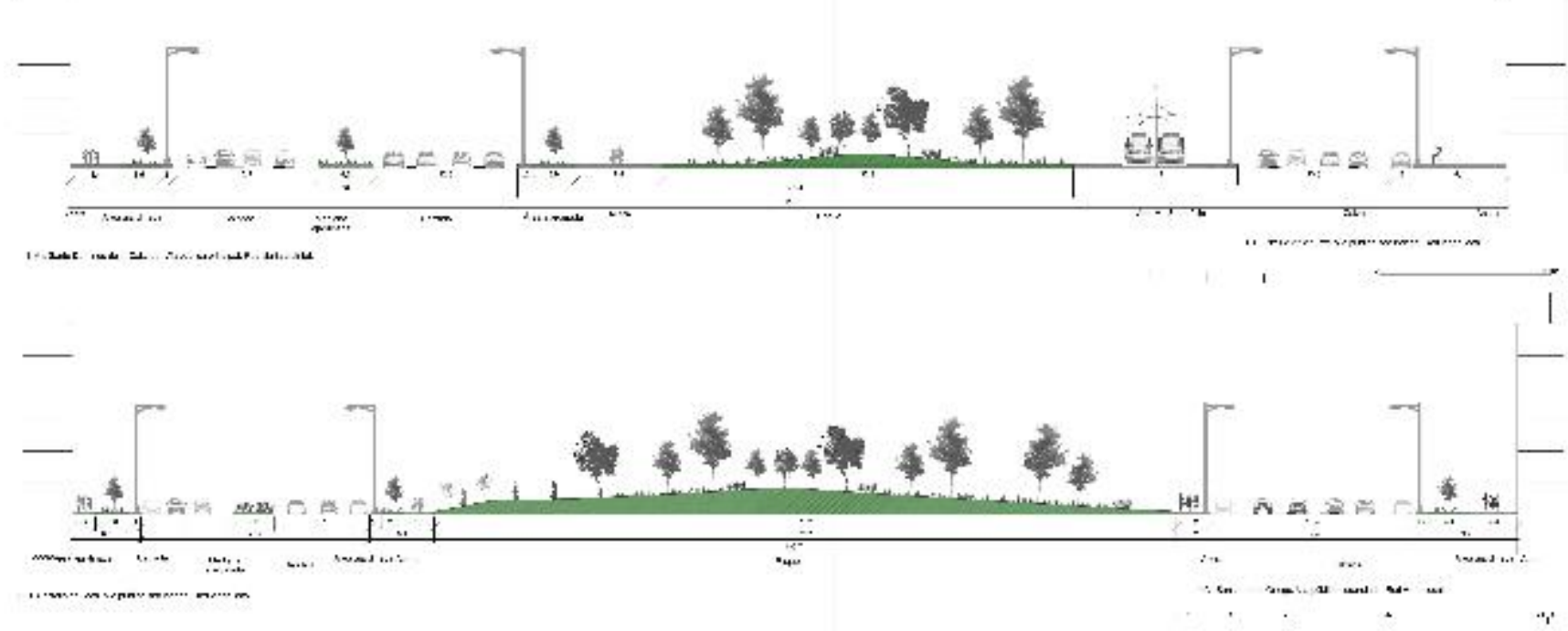

Figura 11. Secciones de dos de los parques lineales de Las Tablas. Las Tablas es un claro ejemplo del papel del espacio público como fragmentador del espacio urbano, donde sus parques lineales - con secciones de entre 44 y 48 metros- dividen físicamente la actuación y desalientan los trayectos peatonales en cuanto significan atravesar largas distancias para realizar actividades cotidianas. 


\subsection{Centralidad fallida.}

El intento fallido de la difusión de la centralidad ${ }^{8}$ del PGOUM97, a través de la creación de nuevas centralidades, que pretendía liberar la presión/concentración terciaria que caracteriza al centro de Madrid se evidencia al darse un paseo por dichos barrios periféricos donde tal vida urbana intensa no existe.

EI PGOUM97 buscaba rellenar aquellos vacíos periféricos carentes de estructura urbana, para conseguir un reequilibrio territorial, que dotaría a la periferia de esos usos generaban los desplazamientos periferia-centro. Sin embargo, en ninguno de los casos estudiados ha podido confirmarse que los desarrollos periféricos hayan sido dotados de los elementos generadores de la complejidad urbana de la ciudad central.

La difusión de la centralidad planteada por el PGOUM97 buscaba actuar como motor de las propuestas estructurantes y a la vez descongestionar el centro de la ciudad sin recurrir a la zonificación. Sin embargo la manera en la que se ha dotado de actividad a los PAU es precisamente a través de actividades especializadas (grandes superficies comerciales, de oficinas o empresariales) desligadas de los demás usos.

\section{La periferia resultante.}

A partir de lo planteado, se comprueban las principales razones por las que el modelo adoptado por los PAU ha fracasado en su propósito de obtener plazo una estructura urbana de reequilibrio de la ciudad.

En ningún momento se duda de la necesidad del desarrollo de dicho suelo para la construcción de viviendas, ya que la necesidad de vivienda asequible en el momento del desarrollo de los planes está ampliamente justificada. Sin embargo, la forma y dimensión que tomaron no fueron las acertadas, tomando en cuenta que se ocuparía todo el suelo vacante del municipio. Tampoco se critica el hecho de que los PAU tengan amplias zonas verdes y vías públicas, pero nos cuestionamos la necesidad de tal magnitud y si responden a un modelo coherente con la ciudad del Siglo XXI, que según lo establecido en la Nueva Agenda Urbana debe de ser compacta, mixta y para todos.

Para entender por que ha sido un modelo fallido, basta con comparar objetivos del PGOUM97 con respecto a Ios PAU y lo que finalmente se obtuvo: no se ha podido solucionar el problema de la vivienda, pues a pesar de que se ha ampliado considerablemente la oferta, se ha demostrado que ese no es el único factor que facilita el acceso a la misma. No se han podido paliar los efectos negativos de los procesos especulativos ni las alzas bruscas de precio de la vivienda. Tampoco se ha logrado difusión de la centralidad ligada al uso mixto del suelo, pues como ya se ha descrito, los usos terciarios se han concentrado en grandes superficies, quitando todo tipo de atractivo a la calle, este último tan necesario para conseguir una vida urbana intensa.

Además, no se ha conseguido es construir un modelo de centralidades periféricas, pues eso que el Plan proponía como difusión de centralidad a través de la previsión de nuevas áreas de oportunidad, se ha quedado en la construcción de centros comerciales o empresariales, elementos que no responden en ningún caso con la acepción tradicional del término centralidad.

Si bien se ha conseguido un incremento de la oferta del suelo urbanizable, este no ha sido dentro de los límites del equilibrio espacial y medioambiental, como se proponía el Plan. El nuevo suelo se ha ordenado sin contemplar la manera más optima de localizar y cuantificar sus usos. El espacio público supera considerablemente lo recomendado. En lo que sí ha sido un éxito es en el propósito de reactivar el sector inmobiliario.

\footnotetext{
${ }^{8}$ Centralidad definida como áreas en las que históricamente ha existido mezcla equilibrada de usos (residenciales, terciarios, comerciales, de servicios, equipamientos, dotaciones, ocio) que ofrecían mayores oportunidades de vida urbana y relaciones sociales intensas (Ezquiaga, 2002).
} 
Retomando los parámetros utilizados para definir al modelo disperso presentados al principio de esta ponencia, se ha podido constatar que efectivamente el modelo urbano derivado de las actuaciones coincide con varios de ellos.

- Densidad: las densidades brutas medias a penas superan las 30 viv/ha y las netas -al restarle las superficies de áreas verdes- no superan las 45 viv/ha. En este caso hay que tomar en cuenta que las densidades mínimas recomendables para permitir concentraciones o nodos de urbanidad se encuentran en el orden de 45-50 viv/ha. Asimismo, para que el transporte público sea económicamente efectivo no pueden manejarse densidades inferiores a 60 o 70 viv/ha.

- Concentración: Esta varía, ya que en Arroyo del Fresno y Montecarmelo los equipamientos y el uso terciario se concentran en puntos extremos de las actuaciones, mientras que en las demás, los equipamientos se distribuyen de manera más uniforme, sin embargo el uso terciario suele ubicarse los lugares de mayor acceso desde el exterior de las actuaciones.

- Mezcla de Usos: Es ineficiente, pues a parte de que se trata de barrios con un fuerte peso residencial, el resto de las actividades suele concentrarse en grandes superficies comerciales o de oficinas, restando actividad a las calles, causando la muerte de la vida urbana.

- Proximidad: Aspectos como la ligera compacidad, las moderadas alturas de las edificaciones, los pequeños fondos edificables de las edificaciones que conforman manzanas con amplios patios interiores y la elevada repercusión de los equipamientos y de los sistemas generales generan un tejido con baja proximidad.

Lo anterior lleva a la conclusión de que las decisiones de planeamiento y de diseño urbano tomadas a partir del PGOUM97 y de los distintos Planes Parciales de las actuaciones han dado como resultado un modelo urbano disperso y de baja densidad, carente de la mayoría de los elementos que dotan a un tejido urbano de la complejidad necesaria para que exista una vibrante vida urbana.

\section{BIBLIOGRAFÍA.}

AYUNTAMIENTO DE MADRID (1982),. Recuperar Madrid. Madrid: Oficina Municipal del Plan- (1985). Plan general de ordenación urbana de Madrid, Memoria General., Madrid: Área de Urbanismo e Infraestructuras. (1997). Plan General de Ordenación Urbana de Madrid 1997. Memoria. Madrid: Gerencia Municipal de Urbanismo. (2009) Plan de Calidad del Paisaje Urbano de la Ciudad de Madrid. Memoria Metodológica, Madrid: Gerencia Municipal de Urbanismo

BARBA, J.J. (2014). Iluminosis en el espacio público de la ciudad contemporánea. Revista Estudios sociales contemporáneos. (10) 11- 24.

BARDAJÍ, E. (2001) De la forma de la ciudad en el planeamiento madrileño. Antecedentes y consecuencias del Plan General de Ordenación Urbana de 1985. URBAN (6), 78-94.

COLEGIO OFICIAL DE APAREJADORES Y ARQUITECTOS TÉCNICOS DE MADRID. Así crece Madrid. Los Nuevos PAU (I) (2004) Revista BIA. Técnicos de Madrid. № 231, julio-agosto.

EWING, R. (2008). Characteristics, causes, and effects of sprawl: A literature review. Urban ecology. Boston: Springer, p. 519-535.

EZQUIAGA, J.M. (2002). Espacio público y nueva topografía periférica. URBAN (7), 112-119.

GALSTER, G., et al. Wrestling sprawl to the ground: defining and measuring an elusive concept. Housing policy debate, 2001, vol. 12, no 4, p. 681-717. 
HENRY, G. (2007). Análisis de costes de la baja densidad. Una lectura desde la sostenibilidad. En: INDOVINA, Francesco (ed). La ciudad de baja densidad Lógicas, gestión y contención, de Barcelona: Diputació de Barcelona.

LÓPEZ DE LUCIO, R., HERNÁNDEZ AJA, A. (1995). Los nuevos ensanches de Madrid: la morfología residencial de la periferia reciente, 1985-1993. Gerencia Municipal de Urbanismo del Ayuntamiento de Madrid. Madrid.

LÓPEZ DE LUCIO, R. (2007). Construir Ciudad en la Periferia Criterios de diseño para áreas residenciales sostenibles. Madrid: Mairea Libros. ( 2012): Vivienda colectiva, espacio público y ciudad: evolución y crisis en el diseño de tejidos residenciales, 1860-2010. Madrid: Nobuko,

MONCLÚS, F. J. (1998). Suburbanización y nuevas periferias. Perspectivas geográfico-urbanísticas. La ciudad dispersa, 5-15.

MUÑIZ, I., GARCÍA LÓPEZ, M., CALATAYUD, D., (2006). Sprawl. Definición. causas y efectos Working Paper 06.03 (Bellaterra: Universitat Autònoma de Barcelona).

VINUESA, Julio, PORRAS, David, RIVA, José Ma, FERNÁNDEZ, Felipe (coords.) (2013). Reflexiones a propósito de la Revisión del Plan general de Madrid (págs. 493-514). Madrid: Grupo TRyS. 